\title{
Squamous Cell Carcinoma of Temporal Bone after Brain Tumor Treatment: A Tricky Diagnosis of a Late Radiotherapy Complication
}

\author{
Thiago Sasso Carmona de Souza ${ }^{1^{*}}$ (D), Ícaro de Almeida Toledo Pires ${ }^{1}$ (D), Nicole Tássia Amadeu ${ }^{1}$ (D), \\ Sara Thaís Steffens ${ }^{1}$ (D), Fellipy Martins Raymundo ${ }^{1}$ (D), Roberta David João de Masi ${ }^{1}$ (D), Rogério \\ Hamerschmidt ${ }^{2}$ (D)
}

${ }^{1}$ Department of Otolaryngology and Head and Neck Surgery - Hospital de Clínicas Complex, Federal University of Paraná, Curitiba, Brazil

${ }^{2}$ Head Chef of the Department of Otolaryngology and Head and Neck Surgery-Hospital de Clínicas Complex, Federal University of Paraná, Curitiba, Brazil

\begin{abstract}
Primary cancer of the External Auditory Meatus (EAM) is a rare disease, with squamous cell carcinoma (SCC) being the most frequent histological type. The invasion of local tissues occurs in most cases, and its treatment is a challenge due to the complex local anatomy. This report presents the case of a 40-year-old patient who presented with a complaint of chronic otorrhea associated with a mass in EAM and a history of treatment of posterior fossa astrocytoma 17 years ago, treated with neurosurgery followed by radiotherapy. The biopsy of the mass showed that it was an invasive SCC. Exposure to previous local radiotherapy is one of the main risk factors for SCC of EAM, in contrast to what happens with cutaneous SCC, which has exposure to solar radiation as the main risk factor. The clinical presentation of the disease is often nonspecific, with otalgia and otorrhea. After diagnosis, the patient underwent surgical treatment with complete resection of the lesion and adjuvant radiotherapy sessions.
\end{abstract}

\section{Keywords}

Temporal bone, Squamous cell carcinoma, Radiation effects

\section{Introduction}

Primary Cancer of the External Auditory Meatus (EAM) is rare, with an incidence of approximately 1 to 6 cases per million per year [1,2]. The Squamous Cell Carcinoma (SCC) is the most frequent histological type, responsible for up to $80 \%$ of cases $[3,4]$. Among the risk factors for the disease are chronic suppurative otitis media, exposure to chemical agents, and previous local radiotherapy, which is the most important factor $[2,5,6]$. These tumors usually have an aggressive behavior, with frequent invasion of adjacent structures and high morbidity and mortality [6]. The primary symptom is otorrhea, which may or not be accompanied by otorrhagia, otalgia and hearing loss $[2,3]$. The non-specific clinic associated with the complexity of the local anatomy makes the temporal bone SCC a major diagnostic and therapeutic challenge $[7,8]$. Some staging systems have been proposed, but the low incidence and the difficulty of the surgical technique contribute to the current lack of systematization for the management of these cases $[7,8]$. The purpose of this article is to report a case of SCC of EAM after brain radiotherapy and its successful surgical treatment.

\section{Case Presentation}

A 40-years-old female patient referred to the Otolaryngology and Head and Neck Surgery Service of a tertiary health center due to right otorrhea for over a year, without improvement with topical treatment. In the previous morbid history, she reported the diagnosis of a choroid plexus astrocytoma of the posterior fossa 17 years ago, with surgical treatment

\footnotetext{
*Corresponding author: Dr. Thiago Sasso Carmona de Souza, Department of Otolaryngology and Head and Neck Surgery Hospital de Clínicas Complex, Federal University of Paraná, R. Gen. Carneiro, 181 - Alto da Glória, Curitiba, Paraná, Brazil, Zip Code: 80060-900, Tell: +55 41999997892

Accepted: November 10, 2020

Published online: November 12, 2020

Citation: de Souza TSC, Pires IAT, Amadeu NT, et al. (2020) Squamous Cell Carcinoma of Temporal Bone after Brain Tumor Treatment: A Tricky Diagnosis of a Late Radiotherapy Complication. J Head Neck Surg 2(1):74-73
} 


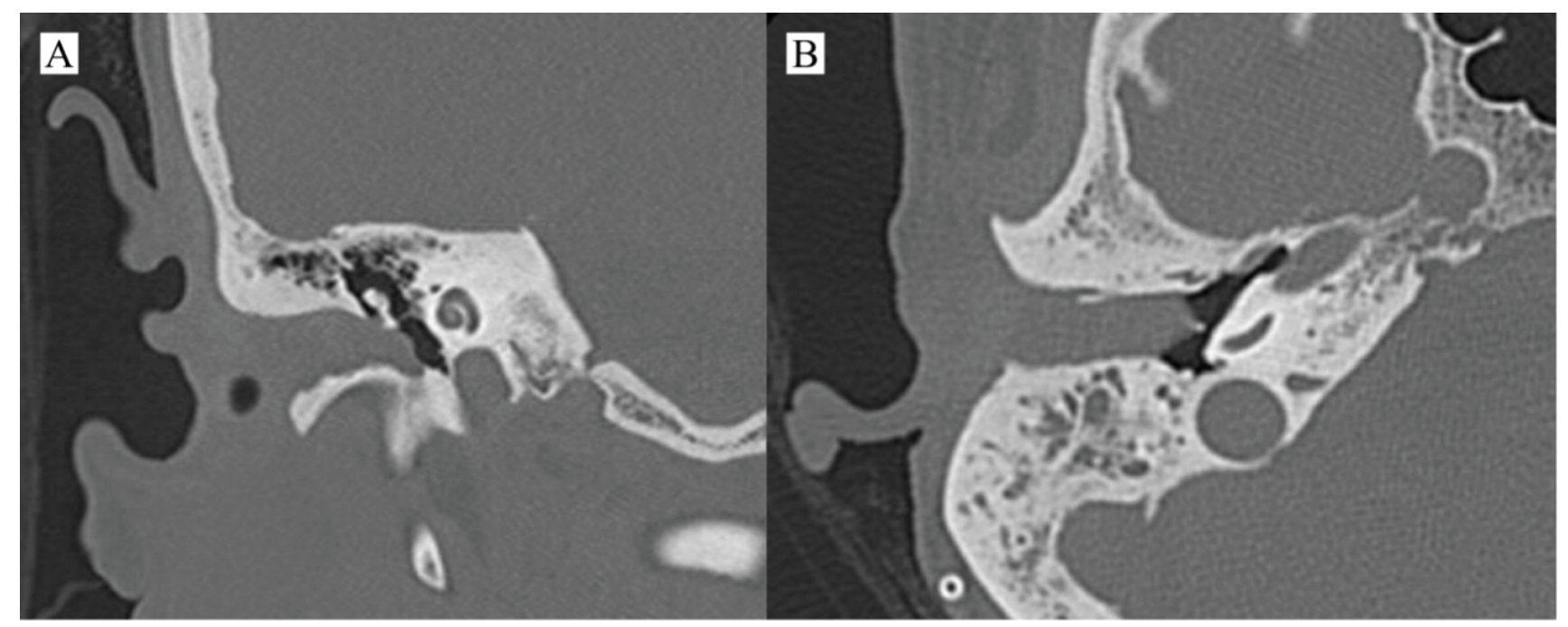

Figure 1: Preoperative coronal (A) and axial (B) CT shows a soft tissue mass obliterating the right external auditory canal, delimited medially by the tympanic membrane, with associated bone erosion.

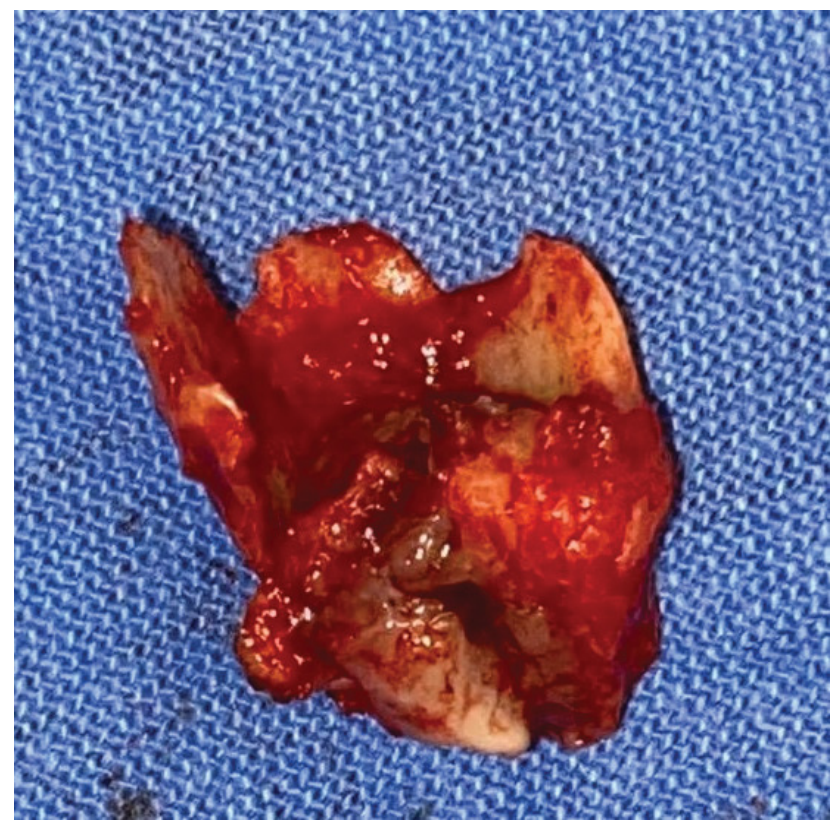

Figure 2: Lateral temporal bone resection, showing the external auditory canal removed en bloc

and adjuvant radiotherapy performed in another service. On otoscopy, a reddish mass obliterating the right EAM was seen. The otorhinolaryngological examination did not reveal any other findings. Computed tomography (CT) images showed a soft-tissue density mass obliterating the right external auditory meatus, with signs of bone erosion, but with no involvement of the middle ear, lymph nodes or distant metastases (Figure 1). Incisional biopsy of the lesion was performed, with histopathological examination showing moderately differentiated invasive SSC. The neck appraisal did not show any clinical or radiological changes that would justify neck dissection or parotidectomy, configuring T2NOMO preoperative staging, according to the Petersburg University System ${ }^{23}$. The patient was then submitted to temporalectomy through lateral resection of the temporal bone (lateral temporal bone resec- tion - LTBR) and auditory canal occlusion with abdominal fat graft (Figure 2). Histopathological examination of the surgical specimen confirmed a moderately differentiated invasive SCC with tumor-free margins and without involvement of mastoid cells. Patient completed the treatment with intensity-modulated radiation therapy (IMRT) and evolved satisfactorily. At 6 months after surgery, no signs of recurrence were found (Figure 3).

\section{Discussion}

Chronic otorrhea is a common complaint in otolaryngology practices. Neoplasic diseases figure among the etiological diagnoses to be remembered in the face of this symptom. As in the case presented, otorrhea is one of the most frequent presentations of ear malignancies, being the most common manifestation of SCC of EAM [7,9]. Other frequent symptoms are otalgia, otorrhagia, dizziness, deafness and facial paralysis [3].

The similarity of these symptoms with benign ear diseases, such as chronic otitis media, in addition to the low incidence of SCC of EAM in clinical practice, often make its diagnosis a true challenge. Commonly, patients are treated during months for ordinary otitis before the proper etiological diagnosis is made, delaying management and leading to progression of the condition to advanced forms of the disease [5].

Ear tumors can originate in the auditory pavilion, external auditory meatus, middle ear and temporal bone. These are rare diseases that affect approximately 1 to 6 per million per year $[10,11]$. They can be primary or metastatic neoplasms. Metastatic lesions are bilateral in more than half of the cases, mainly affecting the petro us apex region $[12,13]$. Regarding primary ear malignancies, they can occur in individuals without clear risk factors or after radiotherapy to treat other intracranial or head and neck malignant lesions $[14,15]$.

A radiation-associated tumor (RAT) is considered to be one that occurs in the irradiated length, without histological relation to the primary tumor and in a period of more than 


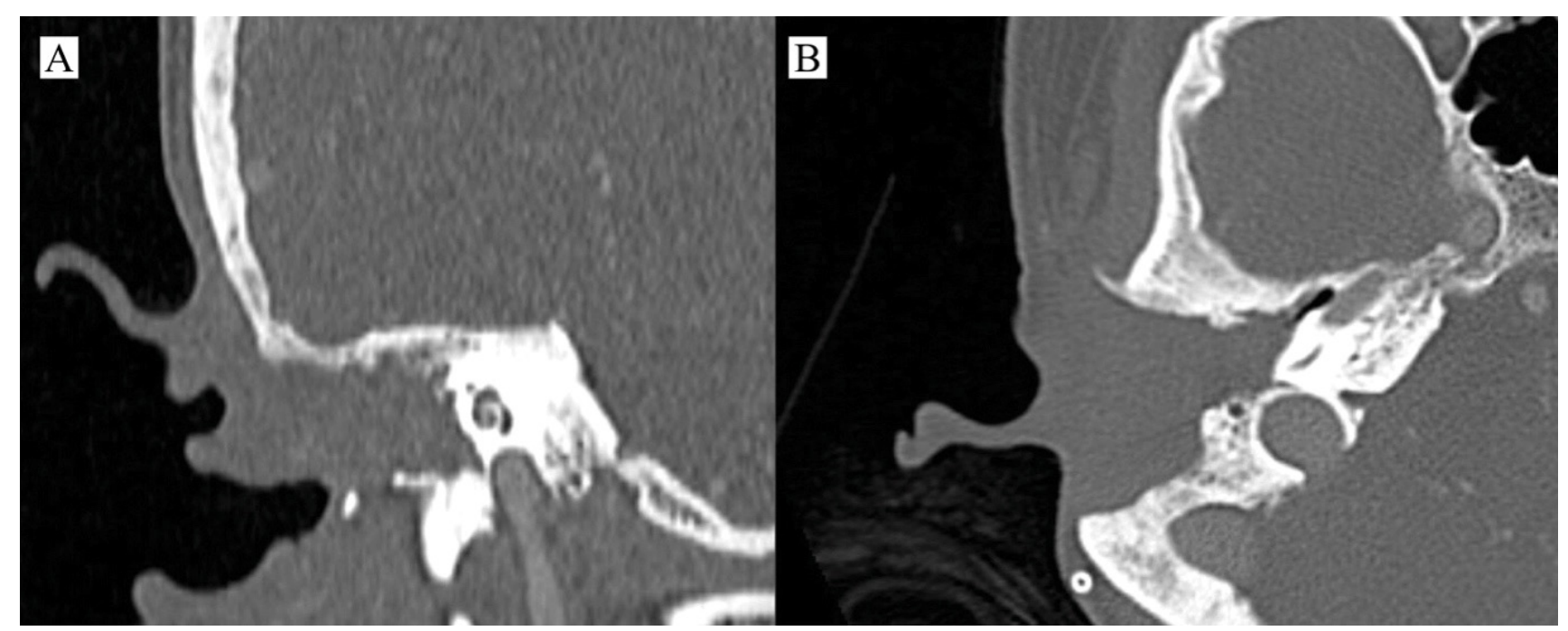

Figure 3: (A) Coronal and (B) Axial CT, 6 months after lateral temporal bone resection and auditory canal occlusion with abdominal fat graft.

5 years after radiotherapy [16]. Lim, et al. described a mean latency period of 13 years between exposure to radiotherapy and the onset of the EAM or the temporal bone RAT. Therefore, our patient will be followed up for indefinite time. Regarding the histological type, SCC is found in about $75-80 \%$ of cases, being adenoid cystic carcinoma, basal cell carcinoma, melanoma and adenocarcinoma are also possible, but less frequent $[9,10]$.

Most of the SCC originating from the EAM affect individuals between the fifth and seventh decade of life, being more prevalent in women $[6,17]$. As opposed to what occurs with the primary SCC of the auricular pavilion, which has the greatest risk factor for chronic sun exposure, the primary SCC of the EAM is associated with chronic suppurative otitis media, exposure to chemicals, and especially prior local radiotherapy, as seen in the case presented $[5,6]$.

The definitive diagnosis of these tumors is made with a biopsy of the lesion [3]. As with the patient's first surgery, it is important to remove the EAM with a normal tissue margin. This approach allows to differentiate the SCC from the pseudoepitheliomatous hyperplasia, an epithelial reaction to chronic inflammation, which can present cellular alterations similar to the SCC in the histological exam [9].

The extension of the disease to the Dura mater, intracranial structures or involvement of cranial nerves are factors associated with a worse prognosis. In addition, the presence of positive lymph nodes and compromised surgical margins have been associated with inferior outcomes [18]. Invasion of the middle ear, a frequent finding due to the aggressive behavior of the SSC, is another important factor of poor prognosis, leading to a reduction in five-year survival rate from $59 \%$ to $23 \%$ [19]. In our case, the patient had no tumor invasion of adjacent structures, giving it a lower stage and a better prognosis.

The tumor's spread occurs via hematogenous and neural pathways [9], and the main affected structures are usually the middle ear, the parotid gland, the auricular pavilion, the temporomandibular joint, the facial nerve, the carotid canal and the jugular fossa [3], being the local extension the main prognostic factor of the disease [9]. The lymph node involvement and distant metastases are rarer than the local invasion, occurring in about $10-20 \%$ of cases. However, the rate of recurrence and local metastases is more common in SCC of EAM when compared to cutaneous SCC in other body locations [20]. For this reason, maintaining postoperative follow-up is essential.

Preoperative staging is performed by clinical examination and imaging tests, with $\mathrm{CT}$ and magnetic resonance imaging being the main methods used [3]. The analysis of local extension and the existence of associated lymph node enlargement are essential for therapeutic planning, since incomplete resection drastically reduces the chance of cure [21]. The survival rate for T2 tumors, as in this case, is $80 \%$ in 2 years and it decreases significantly when the adjacent structures are eroded by the tumor [22].

Local recurrence of the disease is the main cause of therapeutic failure [9], with complete tumor resection and free margins being the treatment of choice for SCC of EAM $[9,23]$. Postoperative indication of radiotherapy for T1 and T2 patients is not clearly consensual at present [23]. Although controversial, studies have shown a tendency towards higher survival and local control rates in patients undergoing adjuvant radiotherapy $[9,23]$, especially when more modern and accurate techniques are performed, such as IMRT [24]. Therefore, after extensive discussion with our oncology and radiotherapy services and considering the patient's age, good clinical condition and the possibility of applying controlled radiation, it was decided to perform adjuvant radiotherapy using the IMRT technique with satisfactorily results. This technique has shown promising results in the treatment of temporal bone SCC, especially in advanced cases [24]. When performed isolated, however, radiotherapy treatment has limited results and is therefore reserved for unrespectable lesions $[3,9,23]$.

The enormous complexity and relevance of anatomical 
Citation: de Souza TSC, Pires IAT, Amadeu NT, et al. (2020) Squamous Cell Carcinoma of Temporal Bone after Brain Tumor Treatment: A Tricky Diagnosis of a Late Radiotherapy Complication. J Head Neck Surg 2(1):74-73

structures potentially involved by tumor growth in this location make surgery a real challenge. In RAT cases there may be an even higher surgical difficulty level. As in the case described, in which the lesion does not extend to the middle ear, most authors recommend LTBR as the choice technique, in which the tissues lateral to the stapes, facial nerve and optic capsule are removed. Local graft closure is indicated as an option to prevent problems in the healing of postoperative wounds, with abdominal fat, chosen by our team for this purpose, being a good option in large resections, avoiding the occurrence of dead space [9].

\section{Conclusion}

SCC of EAM is a disease with aggressive behavior and high morbidity and mortality. Patients previously submitted to radiotherapy in the head and neck are at increased risk for this malignancy, and the temporal bone SSC should always be a diagnostic hypothesis to be considered by the physician when patients with this history seek care for otological complaints such as otorrhea or otalgia. Diagnostic delay is frequent and can significantly compromise survival. Treatment must be individualized, with the best results obtained in patients undergoing temporal bone resection with free margins and adjuvant radiotherapy.

\section{Acknowledgements}

We would like to thank the pathology department of our institution.

\section{Conflicts of Interest}

None declared.

\section{References}

1. Ouaz K, A Robier, E Lescanne, et al. (2013) Cancer of the external auditory canal. Eur Ann Otorhinolaryngol Head Neck Dis 130: 175-182.

2. Baracuhy LV, Fernandes KL (2017) Carcinoma epidermóide de conduto auditivo externo: Uma reconstrução com retalho de esternocleidomastóideo. Rev Bras Cir da Cabeça e Pescoço 46: 64.

3. Gonzalez FM, Paes Junior AJ de O, Tornin O de S et al. (2005) Carcinoma espinocelular do conduto auditivo externo: Estudo por tomografia computadorizada de seis casos. Radiol Bras 38: 181-185.

4. Toriihara A, Masashi Nakadate, Tomoyuki Fujioka, et al. (2018) Clinical usefulness of 18F-FDG PET/CT for staging cancer of the external auditory canal. Otol Neurotol 39: e370-e375.

5. Lim LHY, Yau Hong Goh, Yew Meng Chan, et al. (2000) Malignancy of the temporal bone and external auditory canal. Otolaryngol Head Neck Surg 122: 882-886.

6. Lobo D, Llorente JL, Suárez C (2008) Squamous cell carcinoma of the external auditory canal. Skull Base 18: 167-172.
7. Allanson BM, Low TH, Clark JR, et al. (2018) Squamous cell carcinoma of the external auditory canal and temporal bone: An update. Head Neck Pathol 12: 407-418.

8. Miyawaki H, et al. (1994) Eleven cases of carcinoma of the external auditory canal and middle ear. Pract oto-rhino-laryngologica 75-81.

9. Barrs DM (2001) Temporal bone carcinoma. Otolaryngol Clin North Am 34: 1197-1218.

10. Morton RP, Stell PM, Derrick PP (1984) Epidemiology of cancer of the middle ear cleft. Cancer 53: 1612-1617.

11. Arena S, Keen M (1988) Carcinoma of the middle ear and temporal bone. Otol Neurotol 9.

12. Nelson EG, Hinojosa R (1991) Histopathology of metastatic temporal bone tumors. Arch Otolaryngol Neck Surg 117: 189-193.

13. Gloria-Cruz TI, Schachern PA, Paparella MM, et al. (2000) Metastases to temporal bones from primary nonsystemic malignant neoplasms. Arch Otolaryngol - Head Neck Surg 126: 209-214.

14. Lo WC, Lai-Lei Ting, Jenq-Yuh Ko, et al. (2008) Malignancies of the ear in irradiated patients of nasopharyngeal carcinoma. Laryngoscope 118: 2151-2155.

15. Chowdhary A, Alex M Spence, Lindsay Sales, et al. (2012) Radiation associated tumors following therapeutic cranial radiation. Surg Neurol Int 3: 48.

16. Cahan WG, Woodard HQ, Higinbotham NL, et al. (1948) Sarcoma arising in irradiated bone: Report of eleven cases. Cancer 8-34.

17. Hoshikawa H, Miyashita T, Mori N (2012) Surgical procedures for external auditory canal carcinoma and the preservation of postoperative hearing. Case Rep Surg 1-4.

18. Testa JRG, Fuhuda Y, KowalsIn LP (1997) Prognostic factors in carcinoma of the external auditory canal. Arch Otolaryngol Head Neck Surg 123: 720-724.

19. Bird CR, Hasso AN, Stewart CE, et al. (1983) Malignant primary neoplasms of the ear and temporal bone studied by high-resolution computed tomography. Radiology 149: 171-174.

20. Yoon M, Chougule $P$, Dufresne R, et al. (1992) Localized carcinoma of the external ear is an unrecognized aggressive disease with a high propensity for local regional recurrence. Am J Surg 164: 574-577.

21. Horowitz SW, Leonetti JP, Azar-Kia B, et al. (1994) CT and MR of temporal bone malignancies primary and secondary to parotid carcinoma. AJNR Am J Neuroradiol 15: 755-762.

22. Lobo D, Llorente JL, Suárez C (2008) Squamous cell carcinoma of the external auditory canal. Skull Base 18: 167-172.

23. Shinomiya H, Natsumi Uehara, Masanori Teshima, et al. (2019) Clinical management for T1 and T2 external auditory canal cancer. Auris Nasus Larynx 46: 785-789.

24. Lee N, Puri, DR, Blanco Al, et al. (2007) Intensity-modulated radiation therapy in head and neck cancers: An update. Head Neck 29: 387-400.

DOI: $10.36959 / 605 / 543$

Copyright: (C) 2020 de Souza TSC, et al. This is an open-access article distributed under the terms of the Creative Commons Attribution License, which permits unrestricted use, distribution, and reproduction in any medium, provided the original author and source are credited. 